\title{
SMOS RF Interference Scenario: Status and Actions Taken to Improve the RFI Environment in the 1400-1427 MHz Passive Band
}

\author{
R. Oliva, E. Daganzo, Y. Kerr, S. Mecklenburg, S. Nieto, P. Richaume, C. Gruhier
}

Abstract ESA's Soil Moisture and Ocean Salinity (SMOS) mission is perturbed with Radio Frequency Interferences (RFI) that jeopardize part of its scientific retrievals in some areas in the World, especially over continental areas in Europe, south Asia and the Middle East. Areas affected by RFIs might led to data loss or to underestimation of soil moisture and salinity retrievals, The SMOS team has put in place a few strategies that, one year after launch, have already improved the RFI situation in Europe where half of the sources have been switched off.

Index Terms Soil Moisture and Ocean Salinity (SMOS) Mission, Radio Frequency Interferences, L-Band radiometry, satellite remote sensing.

Manuscript received Month April, 2011. The work was supported by:

R.Oliva and S. Nieto are with the European Space Agency, ESA-ESAC, E-28691 Villanueva de la Cañada, Madrid, Spain (e-mail: Roger.Oliva.Blague@esa.int).

E.Daganzo-Eusebio is with the European Space Agency, ESA-ESTEC, Keplerlaan 1, 2200 AG Noordwijk, The Netherlands.

S.Mecklenburg is with the European Space Agency, ESA-ESRIN, Via Galileo Galilei, Casella Postale 64, 00044 Frascati, Italy

Y. Kerr, P. Richaume and C. Gruhier are with CESBIO (CNES/CNRS/UPS/IRD), 18, avenue Edouard Belin, 31401 Toulouse Cedex 9, France. 


\section{REPLACE THIS LINE WITH YOUR PAPER IDENTIFICATION NUMBER (DOUBLE- CLICK HERE TO EDIT) <}

\section{INTRODUCTION}

ESA's Soil Moisture and Ocean Salinity (SMOS) mission was launched on 2 November 2009. An overview on the objectives of the mission and its status can be found in [1] and [2]. In short, the main scientific objectives of SMOS are to observe soil moisture over land and to observe seasurface salinity over oceans [3-4]. The mission will also provide information for cryospheric applications. At the end of the commissioning phase in May 2010, in which the functionalities of the spacecraft, the instrument and the ground segment were tested, SMOS was declared ready for operations.

As soon as SMOS data analysis began, it became clear that radio frequency interference (RFI) was negatively impacting SMOS data collection. These RFI sources, present over large parts of Europe, China, South Asia and the Middle East, significantly influence the quality of the SMOS data. Detecting and flagging contaminated observations, and contacting national authorities to localize and eliminate point sources emitting in the protected band, present on-going challenges. This paper will outline the effect RFI has on SMOS data, the regulatory situation, and the intended detection and mitigation of RFI contamination.

\section{A. The Instrument: MIRAS}

The SMOS payload MIRAS (Microwave Imaging Radiometer using Aperture Synthesis) is a passive microwave 2-D interferometric radiometer comprising of a central structure $(1.3 \mathrm{~m}$ diameter) and 3 deployable arms extending up to $8 \mathrm{~m}$ in diameter. Each arm is comprised of eighteen L-Band radiometers, complemented by a further twelve radiometers and three Noise Injection Radiometers (NIR) in the central hub. In total, the MIRAS payload comprises 69 


\section{REPLACE THIS LINE WITH YOUR PAPER IDENTIFICATION NUMBER (DOUBLE- CLICK HERE TO EDIT) <}

antennas [5]. SMOS measures the brightness temperature emitted from the Earth at L-band over a range of incidence angles ( 0 to $\left.55^{\circ}\right)$ across a swath of approximately $1000 \mathrm{~km}$ [6-7] with a spatial resolution of 35 to $50 \mathrm{~km}$.

A key requirement in the design of the receivers has been the rejection of signals outside the 1400$1427 \mathrm{MHz}$ passive band. The SMOS RF band pass filter response actually implemented on board the satellite is shown in Fig. 2. The centre frequency of the filter is $1413.5 \mathrm{MHz}$ with a $-3 \mathrm{~dB}$ bandwidth of $20 \mathrm{MHz}$. Furthermore, additional rejection is achieved due to the overall receiver selectivity response (complete receive chain): $\square 32 \mathrm{~dB} @ 1400 \mathrm{MHz}$ and $\square 77 \mathrm{~dB} @ 1397 \mathrm{MHz}$.

The instrument topology and imaging geometry for nominal measurement mode is shown in Fig. 3 ([5]). The satellite control utilizes local normal pointing and yaw steering. The normal to the face of the instrument (the $+x A$ axis) is offset from the nadir direction by a $32 \mathrm{deg}$ tilt in the orbital plane (i.e., a pitch rotation). Yaw steering ensures that the trajectory of all targets is parallel to the ground track velocity vector.

The choice of the operating wavelength for SMOS is determined by the increase in sensitivity of the brightness temperature to soil moisture (ground) and to salinity (ocean) as the observation frequency decreases. The 1400-1427 MHz band (L-Band) is used because it is the lowest passive frequency band allocated to the Earth Exploration Satellite Service (EESS).[1] 


\section{REPLACE THIS LINE WITH YOUR PAPER IDENTIFICATION NUMBER (DOUBLE- CLICK HERE TO EDIT) < \\ II. INTERNATIONAL REGULATION FOR THE PROTECTION OF THE PASIVE BAND}

The SMOS payload, MIRAS, is operating in the passive band 1400-1427 MHz. This frequency band is primary allocation for the Earth Exploration Satellite Service (EESS) -passive, the Radio Astronomy Service and the Space Research Service (SRS) -passive. Figure 3 depicts the allocation of radio communication services in the $1400-1427 \mathrm{MHz}$ band and neighbouring frequencies, as defined by the Radio Regulations at the International Telecommunication Union (ITU) [8].

The EESS (passive) service is leading with the passive reception of natural emissions. The microwave radiometers receive emissions at very low levels compared to those generally handled by other radio communications services; these sensors are therefore generally more susceptible to Radio Frequency Interference (RFI) originated from man-made emitters on the ground, on aircraft or space borne systems.

The issue of RFI within this passive band, especially due to the presence of long-range air surveillance radar systems in nearby bands, has been identified as a key concern by [9]. Observations already performed using airborne campaigns have shown clear instances of RFI signals [10]. Unwanted emissions arising from radars within the adjacent EESS band within the radiometer antenna footprint can easily exceed the maximum emission level allowed. The experience obtained during the operations of SMOS satellite is also showing that the presence of radio-links in nearby bands and unauthorised transmissions within passive band are also a common source of interference for the radiometer [11].

The emissions within these bands are legislated by the competent organisations: 


\section{REPLACE THIS LINE WITH YOUR PAPER IDENTIFICATION NUMBER (DOUBLE- CLICK HERE TO EDIT) <}

Footnote RR 5.340 in the ITU-R Radio-Regulations prohibits all type of emissions in the band 1400-1427 MHz.

Furthermore, the World Radio-communications Conference in 2007 (WRC-07) adopted Resolution 750 on the 'Compatibility between the Earth Exploration Satellite Service (passive) and relevant active services'. This resolution resolves to 'urge administrations to take all reasonable steps to ensure that unwanted emissions of active service stations in the bands and services operating in neighboring bands do not exceed the recommended maximum levels, noting that EESS (passive) sensors provide worldwide measurements that benefit all countries, even if these sensors are not operated by their country'.

\section{RF INTERFERENCE PROBLEM}

\section{A. SMOS Observations}

The presence of RFIs in the SMOS observations was already observed in the first satellite acquisitions as an unnatural and focalised emission, well-above the ground's expected radiation.

The RFI problem is not due to inadequate filtering in the SMOS receiver (which is using less than the allocated frequency band and which boasts very high performance, see section 1), but is due to two specific problems:

- Unauthorised emissions within the protected passive band coming from active sources.

- Unwanted emissions from active services operating in neighbouring bands. 
REPLACE THIS LINE WITH YOUR PAPER IDENTIFICATION NUMBER (DOUBLECLICK HERE TO EDIT) <

Active on-ground antenna within the protected band is observed as a strong point source emission by the SMOS sensors, thus retrieving the frequency impulse response of SMOS in the images. This corresponds to a Dirac's delta with secondary lobes responding to the SMOS hexagonal geometry [12].

Figure 4, a SMOS image, shows the effects of a strong RFI as an off-scale delta in the Brightness Temperature (BT) spatially centred in the on-ground location of the RFI antenna. Also shown are six star-shape tails following the secondary lobes of the SMOS frequency impulse response.

This image shows how the RFI problem in SMOS is not exclusive of the emitters' on-ground location, but can affect much larger areas (up to several hundreds of $\mathrm{Km}$ ) through its secondary lobes. There are more than several RFIs emissions in the World which are up to three orders of magnitude above natural level, effectively blinding the full SMOS field-of-view.

In general, the prejudicial effects of the RFI can be categorized depending on the intensity of the emitting source within SMOS band. Note that the amplitude of the interference varies with the SMOS incidence angle observation, following the RFI antenna pattern. This paper considers the maximum observed emission of those sources:

- Low RFI emission: RFI emissions are same magnitude as natural levels or below. These RFIs are very difficult to detect and can lead to incorrect physical retrievals.

- Moderate RFI emissions: These RFIs emissions are easily detectable, and their effects are only circumscribed to the on-ground emitter's location. In some cases, there may be incidence angle observations, polarizations or specific periods of time that might be immune to the interference. In such cases, retrieval can be performed, but the quality of the data will be affected (less data leading 


\section{REPLACE THIS LINE WITH YOUR PAPER IDENTIFICATION NUMBER (DOUBLE- CLICK HERE TO EDIT) <}

to less accuracy) and obviously quality will also be linked to the ability to efficiently separate affected from non-affected acquisitions. In short, retrieval, in such cases, can be expected to be of poorer quality.

- Strong RFI emissions: These RFI emissions will influence larger areas through the secondary lobes tails. All these areas must be discarded before scientific retrieval.

-Very strong RFI emissions: These RFIs blind the full SMOS field-of-view. The consequence is that the surrounding areas of such RFIs are blanked out to an extent of several hundreds of Km.

When dealing with strong and very strong RFI emission, SMOS tilted observation geometry (see section 1) combined with the characteristics of the on-ground RF emitter -that in the majority of the cases are directed to emit to low incidence angles- will have an impact on the effects of the RFI in the images. Specifically, this impact is observed as a clear difference between ascending and descending passes. While the estimated location of the source based on the centre of the delta will always remain constant, the effects of its secondary lobes will be more severe when the RFI position is ahead of the nadir's satellite track. This characteristic is used as a mitigation technique because areas corrupted by RFI secondary lobes can be observed in either ascending or descending passes - see section III.B- In any case, this difference is only important in areas with a low number of RFIs.

\section{B. RFI Situation Worldwide}

A typical feature of RFI contamination is its non-uniform geographical distribution. Ninety-nine percent of the RFI sources are over land and their distribution depends on whether or not the countries enforce the ITU regulations. For instance, most of America, Australia and a good part of 


\section{REPLACE THIS LINE WITH YOUR PAPER IDENTIFICATION NUMBER (DOUBLE- CLICK HERE TO EDIT) <}

Africa have none or very few sources, while in many European countries and in Asia some areas are severely affected. Figure 5 depicts the global situation in the first weeks of SMOS in orbit.

A feature of the L2 soil moisture processor allowed having statistical information of the retrieval nodes affected by RFI. The detection method consists in a strong RFI screening that detects brightness temperature higher than maximum geophysical expectations (340 K for $\mathrm{X}$ oy $\mathrm{Y}$ polarizations and +/- $50 \mathrm{~K}$ for $\mathrm{XY}$ polarization), followed by a lower RFI screening identifying angular anomalies in the first Stokes parameter. Any of these conditions will raise a counter that will provide a World map probability of RFI contamination.

Figure 6 gives an example of such a map obtained at the beginning of SMOS life. The colour bar corresponds to the probability of any node being affected by RFIs. This scale ranges from red (100\%) indicating that RFIs are always present, to deep blue, indicating none to very low probability. It is easy to spot the impact of a RFI source on the adjoining area. For instance, the very bright source in Spain affected a very large part of Western Africa.

As explained in section 3.a, the effects of RFIs are different in ascending and descending passes. Figure 7 shows the probabilities on Europe for data acquired in ascending or descending passes only.

Experience has shown that in cases with above $10 \%$ probability of RFI contamination, data analysis and usage quickly became difficult. Figure YK6 is an image showing in red how much surface corresponds to above $10 \%$ probability of RFI contamination. 


\section{REPLACE THIS LINE WITH YOUR PAPER IDENTIFICATION NUMBER (DOUBLE- CLICK HERE TO EDIT) <}

As of April 2011, the SMOS team has detected 387 RFI sources distributed throughout the World. Note that some strong RFI sources are masking other ones underneath, and this number is expected to increase as the strong RFIs are switched off.

Figure 9 shows the distribution of these sources per continent, with indication of the strength of the interference observed. Asia and Europe together hold $86 \%$ of the sources in the world and $86 \%$ of the strongest. The American continent is, by comparison much more clean, except for several RFI sources distributed over Canada and United States. Most of these interferers have BT in the range 400-800 Kelvin and their locations appear compatible with known radar networks. Only a few African countries present RFI sources, while Oceania is almost free of them.

Over the oceans there are very few RFIs although SMOS has detected some cases of interferences coming from emitting ships. The main problem for Ocean scientists comes from the secondary lobes of land RFIs near coastal regions. And since the SMOS accuracy requirement for Ocean emissions are higher, a fraction of Kelvin error induces a non-negligible error in salinity.

Figure 10 show an example of how the above mentioned interference emissions from North America affect the salinity retrievals in the northern latitudes. The "black" area corresponds to RFI contamination over the ocean. A similar situation is observed in the Mediterranean Sea as a consequence of emission from Southern European countries. In the current situation, it is impossible to retrieve Sea Surface Salinity in the Mediterranean Sea.

\section{Characterisation of RFI sources}

The analysis of the SMOS observations allows the compiling of some information on the source causing the RF interference. This information includes the strength, geographical location, 


\section{REPLACE THIS LINE WITH YOUR PAPER IDENTIFICATION NUMBER (DOUBLE- CLICK HERE TO EDIT) <}

polarization, directivity orientation of the emission and its periodicity over time. In general, the more information provided to the national entities, the quicker the identification usually occurs.

The power transmitted by a RFI source within the passive band is proportional to the Brightness Temperature measured by the radiometer. In the case of Europe, for example, $44 \%$ of the interferences are moderate sources (Brightness Temperature up to $1000 \mathrm{~K}$ ), 39\% are strong sources (Brightness Temperature between $1000 \mathrm{~K}$ and $5000 \mathrm{~K}$ ) and the $17 \%$ are very strong sources (Brightness Temperature above $5000 \mathrm{~K}$ ).

Geographical location is one of the key elements for identification. The information compiled is defined within an accuracy of up to few km by using algorithms that have been developed for this specific purpose (see section IV.B).

In some cases, the analysis of the satellite data over several passes permits identification of an approximated pointing direction of the RFI antenna by comparing the observed measurements during ascending and descending passes, or the periodicity of observation in case of nonpermanent sources. In this respect, some scanning radars are seen as a RFI pulsed emission through out the SMOS passes, permitting quick identification.

In general, from the SMOS data, it is not possible to identify the type of emission causing the interferences, but the feedback received from several countries helped determine the type of service causing $30 \%$ of the total number of RFIs in Europe. Based on this information, see figure 12 , most of the sources $(52 \%)$ correspond to TV radio-links or other types of radio-links (12\%) such as FM broadcast. Radars represent $28 \%$ of the sources and $4 \%$ are due to wireless camera monitoring systems. 
REPLACE THIS LINE WITH YOUR PAPER IDENTIFICATION NUMBER (DOUBLECLICK HERE TO EDIT) <

\section{Consequences of RFI environment on SMOS retrievals}

Active sources emissions increase the brightness temperature of the area. When the RFI are very bright the pollution can be easily detected and measurements rejected. However, when the emitter is weaker or seen through the side lobes, the signal is simply increased, leading to higher brightness temperatures which in turn will cause the retrieval algorithm to infer lower soil moisture (emissivity decreases when moisture increases) or lower sea surface salinities. As a consequence, strong RFI cause the loss of data and coverage while smaller RFI cause underestimation of soil moisture.

An example of the consequences of RFIs in Soil Moisture retrievals was observed in one of the reference ground sites, the Valencia Anchor Station (VAS) [13] designed to produce match ups for Calibration and Validation activities. VAS is located west of the city of Valencia, in Spain, an area very polluted with RFI contamination (see Figure 7). As a consequence, the results retrieved from SMOS are clearly biased from the on-site measurements (see bottom panel in Figure 13). Top panel of Figure 13 shows the evolution of the retrievals over the VAS sites from mid-summer 2010 until December 2010. The retrievals in this site in Spain had progressively improved on the second half of 2010 responding to the improvements in the RFI situation (see section V.A), but they always retrieve lower soil moisture than the on-site measurements [14]. Ascending and descending differences are also clearly visible in this figure. For comparison, Figure 14 shows a similar matchup analysis obtained over a clean point in the US. There is no marked ascending descending difference and the SMOS observations follow the ground measurements. 


\section{ACTIONS TAKEN TO IMPROVE SMOS RFI ENVIRONMENT}

\section{A. Overview of Short and Medium/Long Term Actions}

Since the SMOS launch it has become clear that the potential impact of RFI on the data provided by the SMOS mission was underestimated and that the strategies planned before launch toned to be reinforced with additional actions and new strategies to overcome the RFI problem.

In order to improve scientific retrieval, the SMOS team is implementing two different short term strategies. The first strategy involves asking for the cooperation of National Spectrum Management Authorities to improve current RFI scenario by investigating the RFI sources and taking adequate action in their territories, usually switching the transmission off in the case of illegal transmissions. A key aspect of this approach is the provision of a good characterisation of the source, see section III.C, so that the spectrum monitoring teams can go on-site and identify the potential sources of the interference observed. ESA regularly provides this information to the national authorities to support further investigations by the regional offices to identify the emitter.

The second approach is to work on data processing strategies to localise and flag the RFI in the data products so as to avoid scientific retrievals from polluted regions. For this, the Level 1 Prototype Processor (L1PP) has been used to test algorithms designed to detect and flag the unwanted emissions observed by SMOS, enabling scientists to prevent making incorrect use of the observations [15]. Moreover, work has been done on the design, implementation and testing of algorithms to remove the effects of the RFI from the measurements by estimating the power of the 


\section{REPLACE THIS LINE WITH YOUR PAPER IDENTIFICATION NUMBER (DOUBLE- CLICK HERE TO EDIT) <}

emission observed. The real benefit of such filtering techniques is still to be proved, in particular for salinity retrieval.

In the medium and long term, it is important to increase the awareness at the international level of the importance to comply with ITU Radio-Regulation, both in terms of prohibiting any emissions in the passive band, and also in terms of respecting the maximum levels recommended for unwanted emissions (in the passive band) due to active services in neighboring bands. The compliance with these levels may require careful maintenance, redesign or improvement of current systems; in some cases this will be achieved depending on refurbishment plans of operating networks. In addition, it is of great importance to ensure constant monitoring of the spectrum by the authorities, as well as monitoring of the retrieved data by the science teams, to identify data polluted by RFI and to trigger adequate actions. It is important to remember that, as outlined within this paper, the removal of strong RFIs does not mean that the band will be free of interference, since low levels can still exist and create erroneous data retrieval [11].

\section{B. RFI Detection and Geo-location}

Requesting national authorities to enforce the law by switching off the illegal transmitters is the preferred method to reduce the contamination from RFIs in SMOS images since it eliminates the root of the problem. However this procedure is rather time consuming and needs the cooperation of the national authorities.

Providing accurate coordinates of the RFI sources is key in helping the national frequency departments locate the origin of the illegal emissions. However, SMOS spatial resolution varies from $35 \mathrm{~km}$ at nadir, to $55 \mathrm{Km}$ in the higher incidence angles. On top of that, as seen in section 


\section{REPLACE THIS LINE WITH YOUR PAPER IDENTIFICATION NUMBER (DOUBLE- CLICK HERE TO EDIT) <}

III.B, certain countries around the World are very populated with RFIs, which makes it difficult to discern between the real position of the multiple RFIs and the observed interferences coming from the multiple tails of all the RFIs within the field-of-view. Therefore, providing accurate on-ground coordinates is a real challenge.

Nevertheless, a detection algorithm was developed to automatically obtain the on-ground position of all RFIs above a certain threshold from the SMOS geo-located BT operational products. The detection algorithm scans the SMOS images for local maximums above the natural emission levels. When a local maximum is found, the algorithm discriminates the emissions coming from secondary lobes from strong sources in the aliases regions by the relative velocity observed within the alias-free field of view.

Good accuracy in the coordinates of the detected RFIs is achieved by: 1) using only the region close to nadir, where the pixel footprint projection is minimum 2) by fitting a Gaussian shape signal to the retrieved BT levels around the local maximum and retrieving its estimated centre position and 3) by averaging all the retrieved positions in multiple pass information.

This technique has been analysed with the feedback received by the national authorities following ESA's first estimated coordinates. The results show that the sources were found within a $5 \mathrm{~km}$ radius from the retrieved coordinates in $88 \%$ of the cases. See figure 15 of all the examples received.

\section{Notification and Follow-up Procedure}




\section{REPLACE THIS LINE WITH YOUR PAPER IDENTIFICATION NUMBER (DOUBLE- CLICK HERE TO EDIT) <}

Following a careful analysis of the retrieved data, ESA has prepared a RFI catalogue with detailed information of the geo-location, estimated strength, and type of transmitter for all RFI sources, organised per countries. This information is typically provided together with a snapshot of SMOS observations over the area of interest. The catalogue is updated regularly and allows ESA to keep track of the process in the identification and switching-off of RFI sources.

ESA contacts the national spectrum management authorities and provides the RFI catalogue information for the relevant country. The authorities normally distribute the RFI sources per regions, and then delegate regional offices the tasks of investigation and onsite monitoring of the reported RFI locations.

Should the source be due to an illegal transmission (either an intentional or unintentional emission in the passive band), then the authorities request the immediate stop of the emission. When found that the RFI is due to out-of-band emissions of active services in neighbouring bands, the authorities initiate investigations of the equipment performance. In some cases the problem was found in harmonic emissions of malfunctioning equipment, or a shift in the centre frequency of operation due to poor maintenance practices. The frequency management national authorities initiate adequate action depending on the cases, and are in regular contact with ESA to get updated RFI information based on the latest satellite observations.

\section{Lobbying at International Level to Increase Awareness of the RFI Problem and}

\section{Improving the Regulatory Framework}

The problem of SMOS RFI has been reported by ESA at different forums with several purposes: 


\section{REPLACE THIS LINE WITH YOUR PAPER IDENTIFICATION NUMBER (DOUBLE- \\ CLICK HERE TO EDIT) <}

1) To increase awareness about the detrimental effect of RF interference in world-wide scientific observations;

2) To request the cooperation in the investigations and follow up by the National Frequency Regulatory Authorities; and

3) To improve the regulatory framework protecting the operation in the $1400-1427 \mathrm{MHz}$ passive band.

At the international level, ESA has presented contributions at ITU (working group WG-7C on passive sensors), the Committee on Space Research (COSPAR), the Space Frequency Coordination Group (SFCG), and various conferences (i.e. OCOSS, IGARSS, EGU).

The evolution of SMOS RFI scenario has also been regularly reported at the CEPT Frequency Management Working Group meetings $\left(68^{\text {th }}, 69^{\text {th }}, 70^{\text {th }}\right.$ and $71^{\text {st }}$ WGFM) and it has been brought to the attention of Radio Spectrum Policy group at the European Commission.

\section{RESULTS:}

\section{A. Improvements of SMOS RFI Scenario Following Elimination of Sources}

The progress of the RFI scenario from the start of the mission has achieved increasingly good results as the different countries got involved, see figure 16. As of April 2011, 13 ESA member states were contacted, 12 from other European countries, and 10 from the rest of the World. The total number of RFIs switched off was 82, mainly those in Europe. Figure 16 provides an overview 


\section{REPLACE THIS LINE WITH YOUR PAPER IDENTIFICATION NUMBER (DOUBLE- CLICK HERE TO EDIT) <}

of European countries in which as a whole $50 \%$ of the detected RFI sources have been switched off.

Actually, in Europe, the best progress has been achieved in some of the countries that polluted the most, such as Spain, UK, Greece and Italy. It is also worth mentioning the few countries that have cleaned up their territories: Finland, Denmark, Germany and Iceland. Otherwise, Turkey has the largest number of active RFI sources. ESA is in contact with the Turkish authorities and investigations have been initiated.

The effects of this effort were almost immediately visible on the data as depicted in figures 18 in which it is shown that in a period of less than one year European countries drastically reduced their emission.

Although there is still much work to be done, ESA is confident that the situation will continue improving over the near future.

\section{B. Lobbying Results}

The evidence of RFI corruption at levels that prevent geophysical measurements is the rationale for having compulsory, not just recommended limits, that protect this passive band. The CEPT Electronic Communications Committee (ECC) has recently approved (March 2011) a new decision $\mathrm{ECC} / \mathrm{DEC} /(11) \mathrm{AA}$ on "the protection of the EESS (passive) service in the $1400-1427 \mathrm{MHz}$ band". This ECC decision has been developed with the aim of providing long-term coexistence conditions between active services operating below $1400 \mathrm{MHz}$ or above $1427 \mathrm{MHz}$, and the earth 


\section{REPLACE THIS LINE WITH YOUR PAPER IDENTIFICATION NUMBER (DOUBLE- CLICK HERE TO EDIT) <}

exploration satellite service (EESS) (passive) in the band 1400-1427 MHz. The decision translates the compatibility criteria recommended by ITU Res. 750 (WRC-07) into mandatory limits and intends to give a clear sign to the international community about the recognition by CEPT of the societal and economical values of the EESS (passive) applications related to climate change and natural disasters prediction. The unwanted emissions limits shall apply to stations in the active services operating in CEPT countries in the $1350-1400 \mathrm{MHz}$ and $1427-1452 \mathrm{MHz}$ bands brought into use after 1st January 2012. Each CEPT administration will have to decide when the decision is nationally implemented. SMOS, and in particular future Earth Observation (EO) missions operating in the 1400-1427 MHz passive band, will benefit from this decision.

COSPAR has also recognised the importance of complying with the regulatory frame protecting the passive band $1400-1427 \mathrm{MHz}$, and has requested all COSPAR national representatives to contact responsible agencies within their countries in order to take necessary measures to eliminate unauthorized contaminating sources relating to the SMOS mission.

The European Commission (RS-COM 2010) has also recognized the importance of strengthening the cooperation of all EU member states in the investigation of the RFI sources over their territories and of taking action to remove, as much as possible, the remaining interferences.

\section{CONCLUSION}

Contamination due to RF interferences observed by the SMOS satellite has exceeded expected levels, especially in Europe, Asia and the Middle-East. Of special concern is the unauthorised 


\section{REPLACE THIS LINE WITH YOUR PAPER IDENTIFICATION NUMBER (DOUBLE- CLICK HERE TO EDIT) <}

emissions observed within the protected passive band [1400-1427 MHz] that can completely blank out the SMOS field-of-view. The polluted data will be lost in most cases or will degrade the scientific retrievals at best. This data is important economically for weather forecast and extreme event prevention, and it has no real substitute [itu reference (rs.2178].

Since SMOS satellite was launched a lot of effort has been put in place in order to reduce the number of RFI. The situation has improved in Europe where half of the active sources have been switched off, but there is still a lot of work to do. The cooperation of the National Frequency Management Authorities is key to ensure both, an improvement of SMOS RFI scenario over the territory, and also the compliance with the existing regulatory framework to protect the passive EESS band 1400-1427 MHz.

All this effort has to be continued and intensified by finding new ways to identify and characterise the RFI sources, and by raising concern among the different countries and organisations about the implications of the RFI in the science observations.

\section{ACKNOWLEDGMENTS:}

To SMOS Team, in particular Manuel Martin Neira, principal engineer; ESA Frequency Manager, Mr Edoardo Marelli; Mr Jean Pla from CNES and Mr P. Tristant from MeteoFrance, for their valuable comments and continuous work for the protection of the EESS passive bands. Per organizations:

ESA appreciates the support and involvement in the investigation of RFI sources by all National Frequency Regulation Authorities, and in particular Mr J.C. Vallejo, from the Dirección General 


\section{REPLACE THIS LINE WITH YOUR PAPER IDENTIFICATION NUMBER (DOUBLE- CLICK HERE TO EDIT) <}

de Telecomunicaciones (Spain). Other persons to be considered in this acknowledgment: $\mathrm{Mr} \mathrm{G}$ Ducheyne and $\mathrm{Mr}$ F Vindevoghel, from the Belgisch Instituut voor postdiensten and telecommunicatie (Belgium); Mr H Blume, from the Danish National IT and Telecom Agency (Denmark); Mr. Joni Kallio from the Finnish Communications Regulatory Authority and Mr J Kainulainen at Aalto University (Finland); Mr J Guyomard from ANFR (France); Mr J Nitschke from BNetZA (Germany); Mrs Mrs Irini Athanassiou from the Ministry of Transport and Communication (Greece); Mr D Spoto from the Ministero dello Sviluppo Economico and Mr S Mirfa from the Defense Ministry (Italy); MR M. van Rouwendal Ministerie van Defensie and $\mathrm{Mr}$

L Ket from the Dutch radiocommunications agency (The Netherlands); Mr B Dudhia from OfCom (UK); Mr Thorleifur Jónasson from Post- \& Telecom Administration of Iceland; Mr W Marczewski from Centrum Badan Kosmicznych PAN, Zaklad Teledetekcji and Mr Jerzy Andrzejczak from UKE (Poland); Mr F Yurdal from ECC-WGFM and Mr Tayfun Acarer from Bilgi Teknolojileri ve İletişim Kurumu (Turkey); $\mathrm{Mr} \mathrm{Wu}$ and $\mathrm{Mr}$ Zhang (CSSAR); and the Chinese NRSCC, CSSAR and MIIT; Mr E Cherian from Federal Comms Commission (United States) and Mr LY Bun-Ret and Mr A Ongaro, from Spectrum, Information Technologies and Telecommunications Sector (Canada).

\section{REFERENCES}


REPLACE THIS LINE WITH YOUR PAPER IDENTIFICATION NUMBER (DOUBLE-

CLICK HERE TO EDIT) <

[1]: Y.Kerr, P.Waldteufel, J.P.Wigneron, J. M. Martinuzzi, J. Font, and M. Berger, "Soil moisture retrieval from space: The Soil Moisture and Ocean Salinity (SMOS) mission," IEEE Trans. Geosci. Remote Sens.,vol. 39, no.8, pp. 1729-1735, Aug. 2001.

[2]: S. Mecklenburg, M. Drusch, Y. Kerr, J. Font, M. Martin-Neira, S. Delwart, G. Buenadicha, N. Reul, E. Daganzo-Eusebio, R. Oliva, R. Crapolicchio, “ESA's Soil Moisture and Ocean Salinity Mission: An overview after one year of operations”, this Special Issue, 2011.

[3]: Mission Objectives and Scientific Requirements of the Soil Moisture and Ocean Salinity (SMOS) Mission (MRD), EEOM-SMOS-MRD, issue 5.

[4]: The Changing Earth - New scientific challenges for ESA's Living Planet Programme, ESA Publication, SP-1304, July 2006.

[5]: McMullan, K.D., M. Brown, M. Martin-Neira, W. Rits, S. Ekholm, J. Marti and J. Lemanczyk, “SMOS: The Payload”. IEEE Geosci. Remote Sens., 2008. 46(3).

[6]: Kerr, Y.H., The SMOS Mission: MIRAS on RAMSES. A proposal to the call for Earth Explorer Opportunity Mission. 1998, CESBIO: Toulouse (F). p. 50.

[7]Kerr, Y., J. Font, P. Waldteufel, A. Camps, J. Bara, I. Corbella, F. Torres, N. Duffo, M. Vallilossera and G. Caudal. New radiometers: SMOS-a dual pol L-band 2D aperture synthesis radiometer. in Aerospace Conference Proceedings, 2000 IEEE. 2000. 


\section{REPLACE THIS LINE WITH YOUR PAPER IDENTIFICATION NUMBER (DOUBLE- \\ CLICK HERE TO EDIT) <}

[8]: Vol I (Articles) of the Radio Regulations, International Telecommunications Union, Edition of 2008 [available through the ict regulation toolkit under http://www.ictregulationtoolkit.org/en/PracticeNote.aspx?id=2824]

[9]: Committee on Scientific Use of the Radio Spectrum, Committee on Radio Frequencies and National Research Council. "Spectrum Management for Science in the 21st Century", The National Academies.

[10]: M. Zribi, M. Parde, J. Boutin, P. Fanise, D. Hauser, M. Dechambre, Y. Kerr, M. LeducLeballeur, G. Reverdin, N. Skou, S. Sobjaerg, C. Albergel, J. C. Calvet, J. P. Wigneron, E. LopezBaeza, A. Rius and J. Tenerelli, "CAROLS: A New Airborne L-Band Radiometer for Ocean Surface and Land Observations," Sensors, vol. 11, pp. 719-742, Jan 2011.

[11]: E. Daganzo, J. Pla, Y. Kerr, M. Martin-Neira, R. Oliva, E. Marelli, S. Mecklenburg, B. Rommen, M. Brown, P. Richaume and C. Gruhier, "Characterisation of SMOS RF Interferences in the 1400-1427 MHz band as detected during the commissioning phase," in OCOSS (Ocean and Coastal Observation, Sensors and Systems), Brest France, 2010

[12]: I. Corbella, F. Torres, A. Camps, N. Duffo, M. Vall-llossera, "Brightness-Temperature Retrieval Methods in Synthetic Aperture Radiometers » IEEE Transactions on Geoscience and Remote Sensing, Vol. 47, No 1, January 2009

[13]: S. Delwart, C. Bouzinac, P. Wursteisen, M. Berger, M. Drinkwater, M. Martin-Neira and Y. Kerr, "SMOS Validation and the COSMOS campaigns," IEEE Transactions in Geoscience and Remote Sensing, vol. 46, pp. 695-704, 2008. 


\section{REPLACE THIS LINE WITH YOUR PAPER IDENTIFICATION NUMBER (DOUBLE- CLICK HERE TO EDIT) <}

[14]: S. Juglea, Y. Kerr, A. Mialon, J. P. Wigneron, E. Lopez-Baeza, A. Cano, A. Albitar, C. Millan-Scheiding, M. C. Antolin and S. Delwart, "Modelling soil moisture at SMOS scale by use of a SVAT model over the Valencia Anchor Station," Hydrology and Earth System Sciences, vol. 14, pp. 831-846, 2010.

[15]: R. Castro, A. Gutierrez, P. Vieira, J. Barbosa. “A first set of techniques to detect Radio Frequency Interferences and mitigate their impact on SMOS data”, this Special Issue 2011 


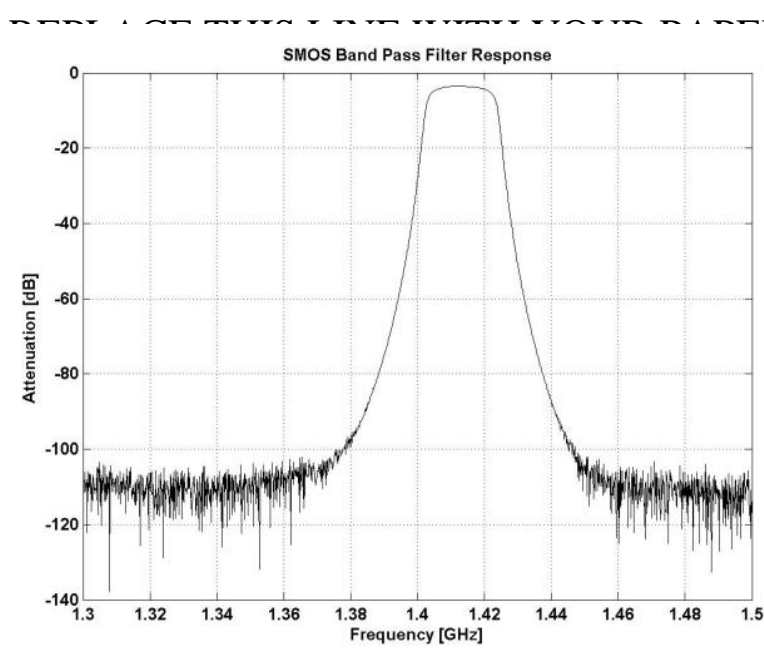

TEI

E-

Figure 1: SMOS RF-Bandpass filter response

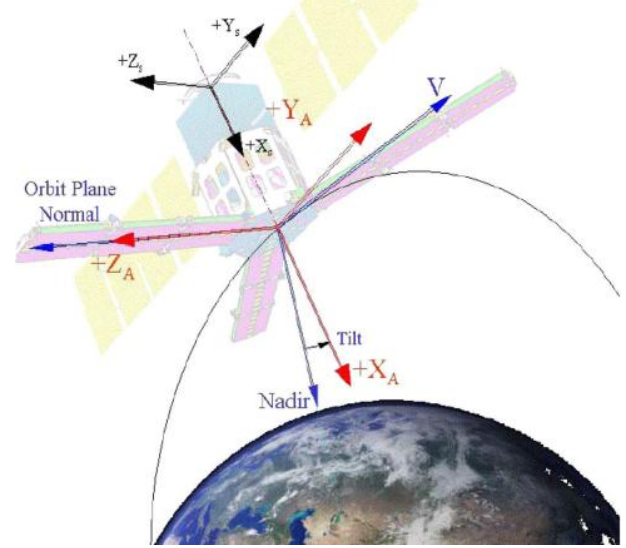

Figure 2: SMOS measurement

observation mode geometry. Ref [5]

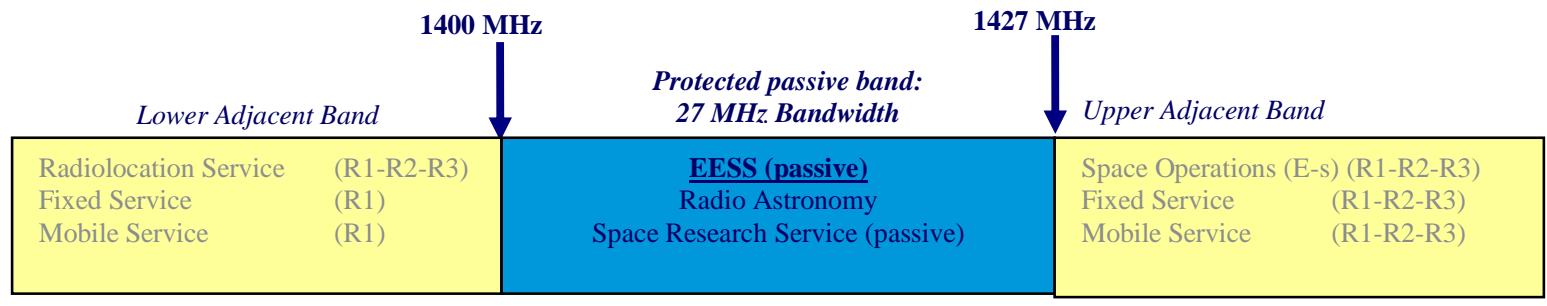

Figure 3: Schematic about frequency allocation to the EESS passive in the 1400-1427 MHz band

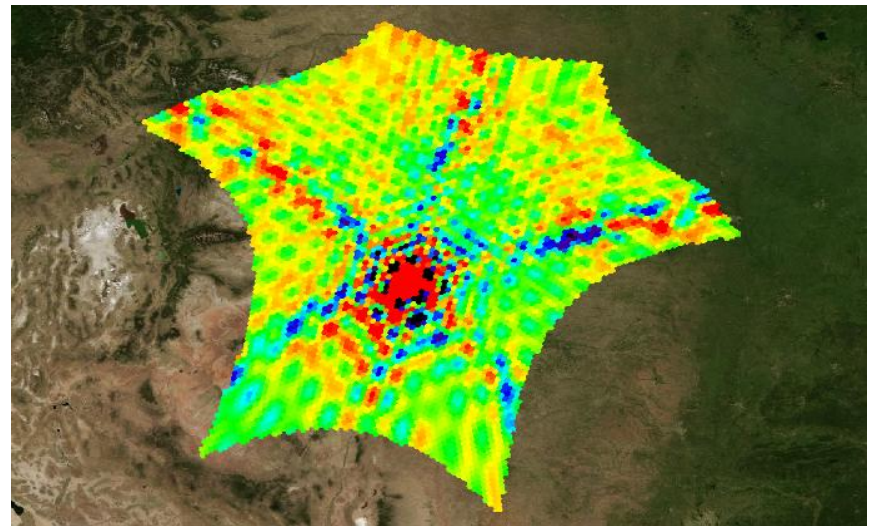

\section{Brightness Temperature [K]}

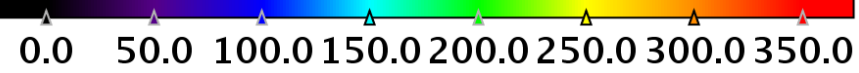

Figure 4: SMOS snapshot of a very strong RFI emission. 
REPLACE THIS LINE WITH YOUR PAPER IDENTIFICATION NUMBER (DOUBLECLICK HERE TO EDIT) <
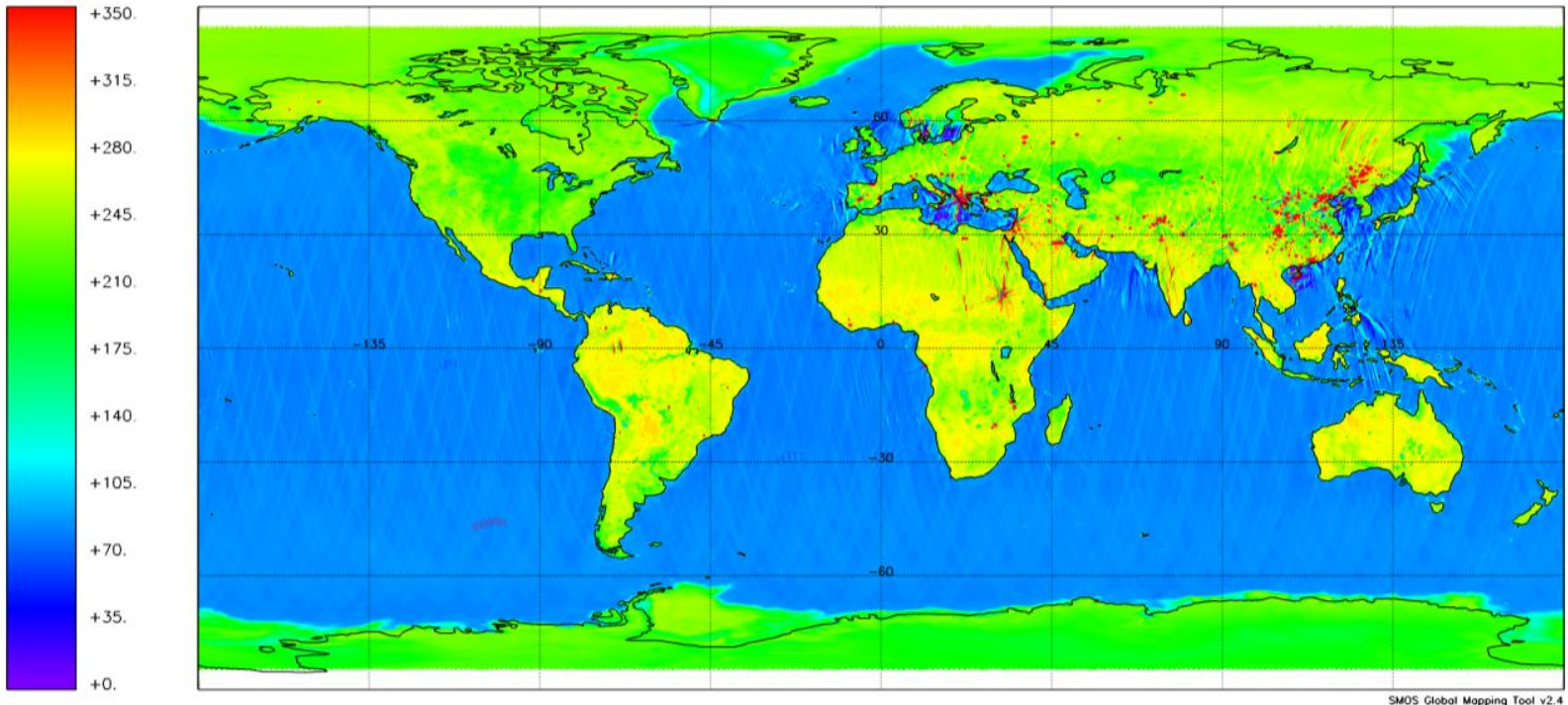

Figure 5: SMOS global brightness temperature image observed in the first weeks of the satellite

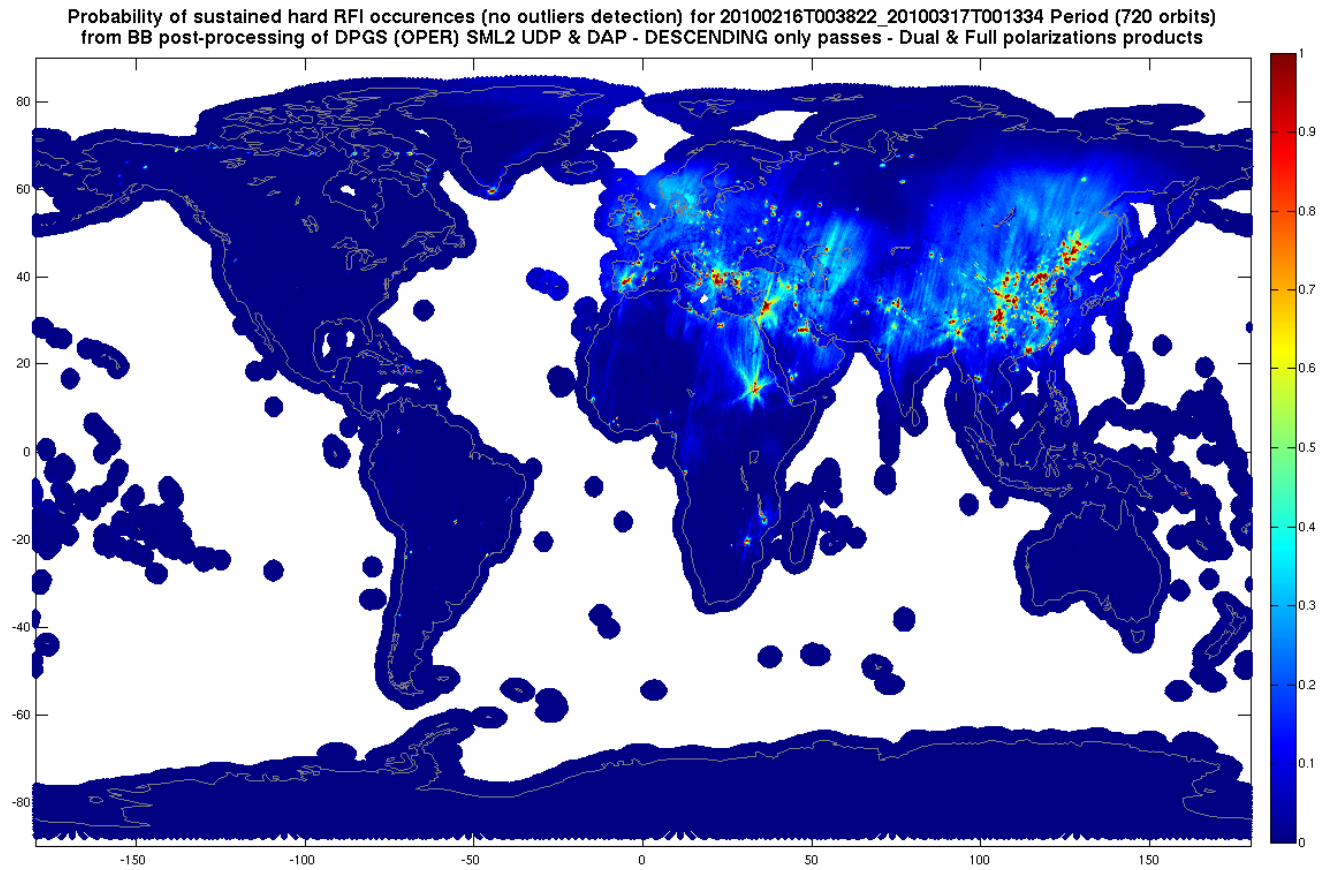

Figure 6: RFI contamination probability map derived in the first month of the mission. 
REPLACE THIS LINE WITH YOUR PAPER IDENTIFICATION NUMBER (DOUBLECLICK HERE TO EDIT) <
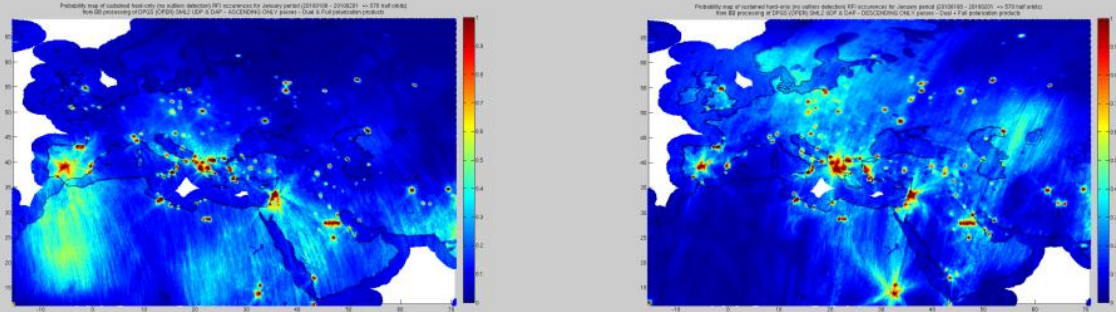

Figure 7: RFI contamination probability map derived from ascending passes (left) or descending passes (right)
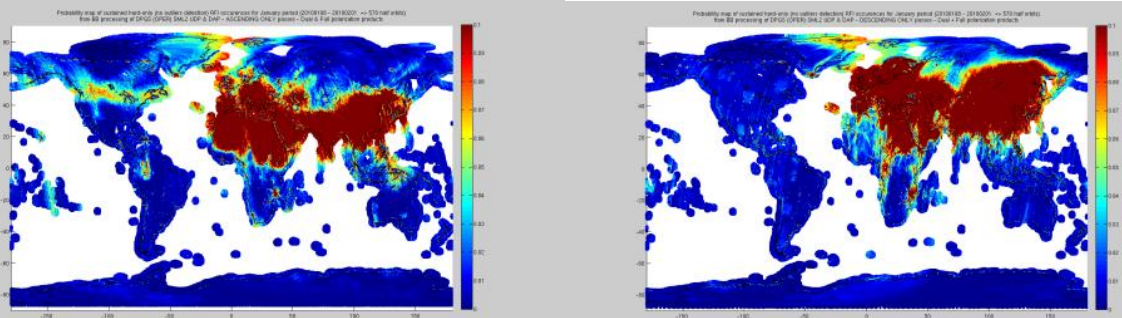

Figure 8: World RFI contamination probability map scaled form 0 to $0.1 \%$

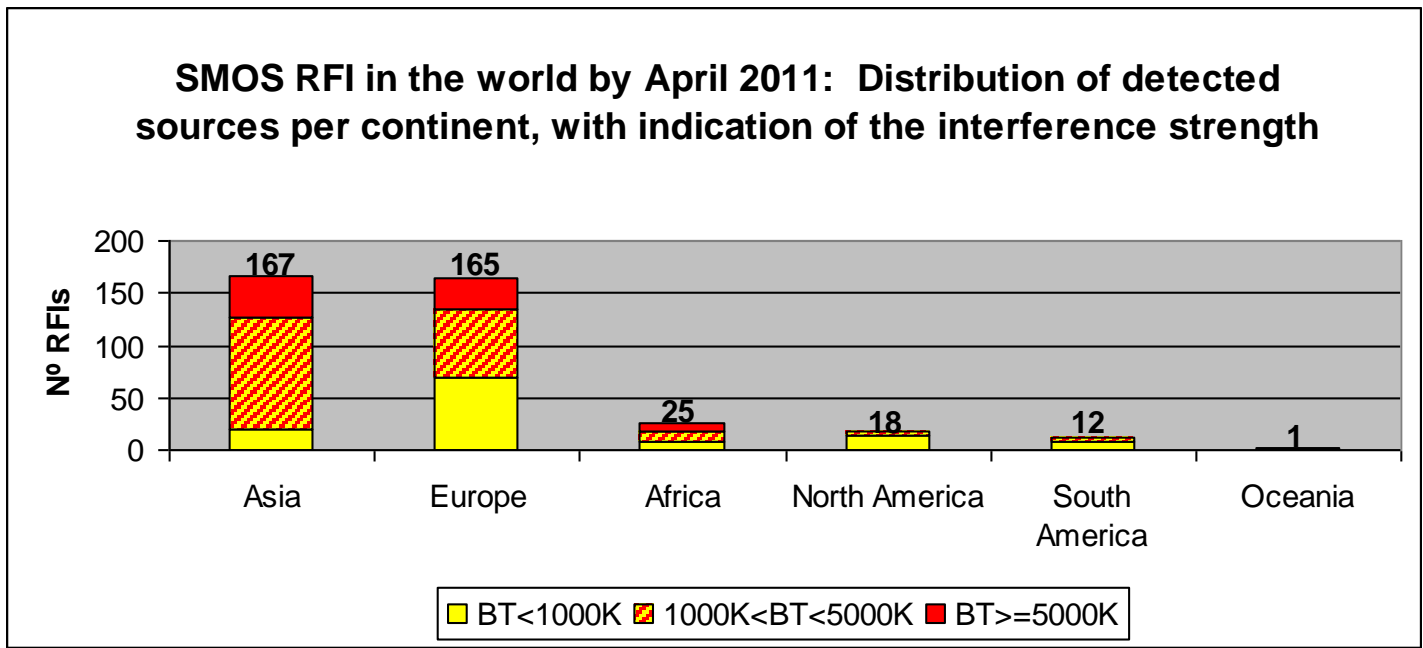

Figure 9: Distribution of detected sources per continent 


\section{REPLACE THIS LINE WITH YOUR PAPER IDENTIFICATION NUMBER (DOUBLE- CLICK HERE TO EDIT) <}

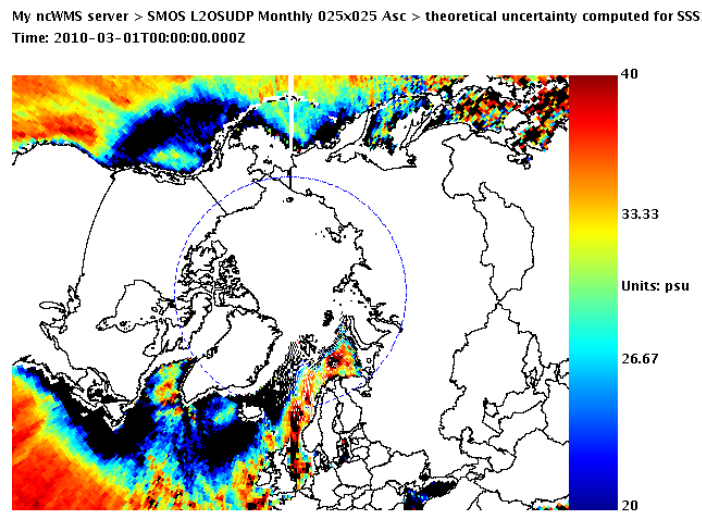

Figure 10: Sea surface salinity retrievals over oceans in the northern Polar Regions. Credit: $N$. Reul

SMOS RFI in Europe by March 2011:

Distribution of sources per country, with indication of the interference strength

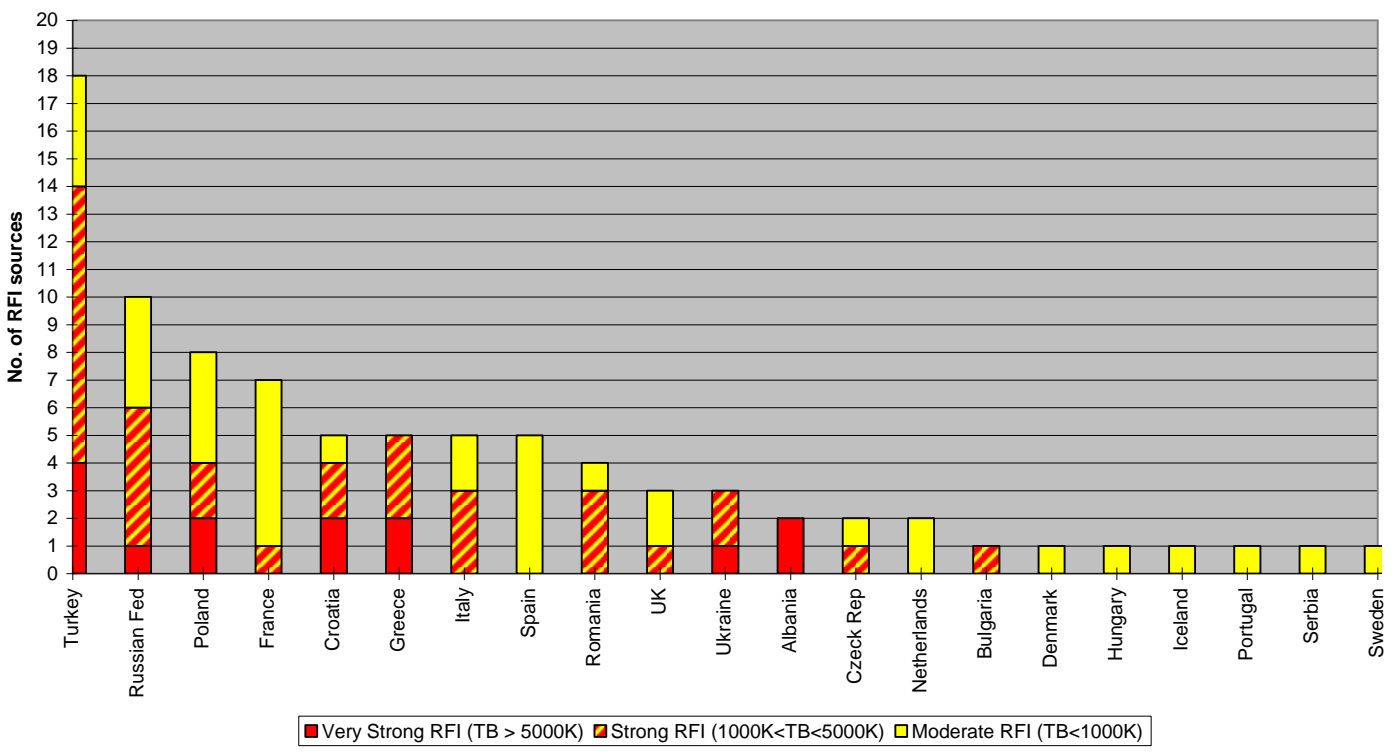

Figure 11: Distribution of active sources in Europe as of March 2011. 
REPLACE THIS LINE WITH YOUR PAPER IDENTIFICATION NUMBER (DOUBLECLICK HERE TO EDIT) <

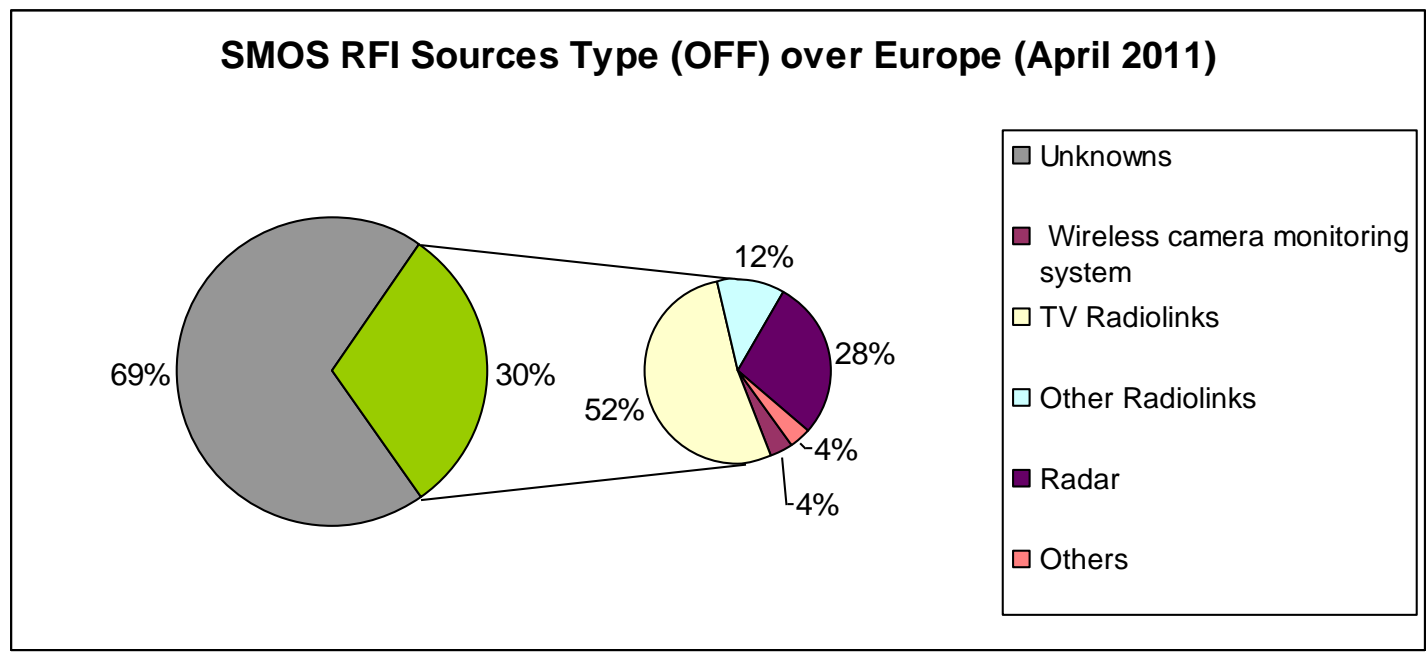

Figure 12: Distribution of the type of services of the RFI sources detected
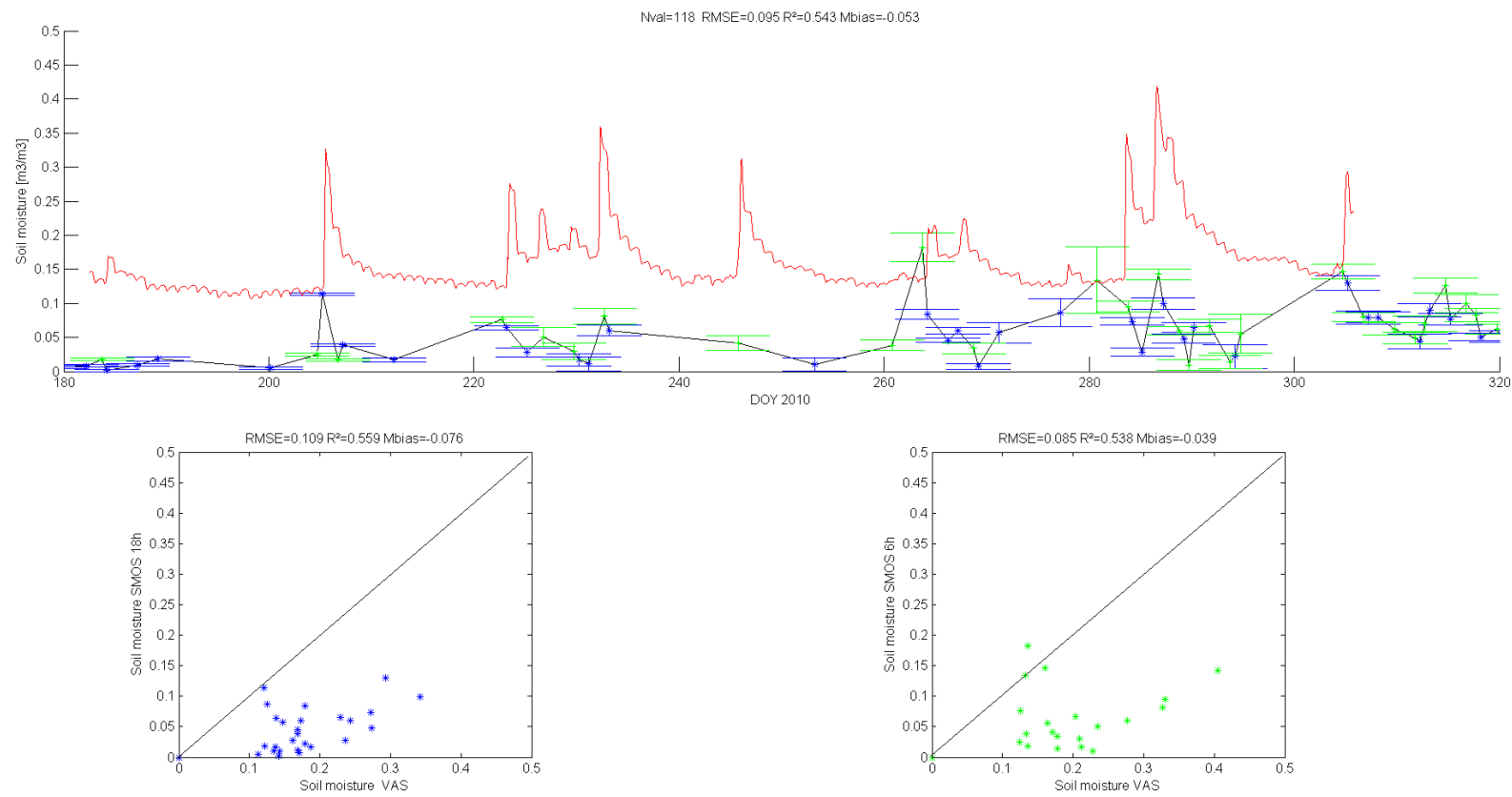

Figure 13: Retrievals over the VAS site from June to December 2010. Top panel temporal evolution of the spatialised soil moisture (red) the SMOS retrievals (in green ascending (6am) and in blue descending (6pm). Bottom panel corresponding scatter plots 
REPLACE THIS LINE WITH YOUR PAPER IDENTIFICATION NUMBER (DOUBLECLICK HERE TO EDIT) <

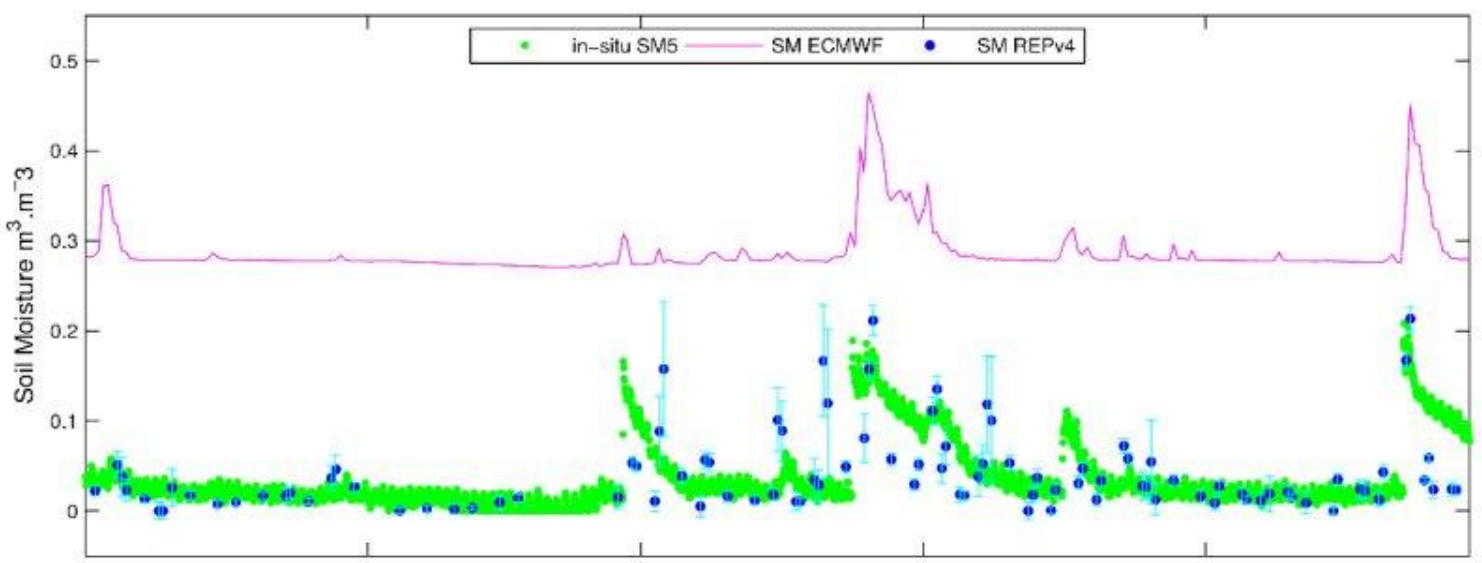

Figure 14 retrievals over a site with no RFI. Scan site in the US. in magenta the ECMWF soil moisture, in green ground measurements and in blue (dots) SMOS retrievals

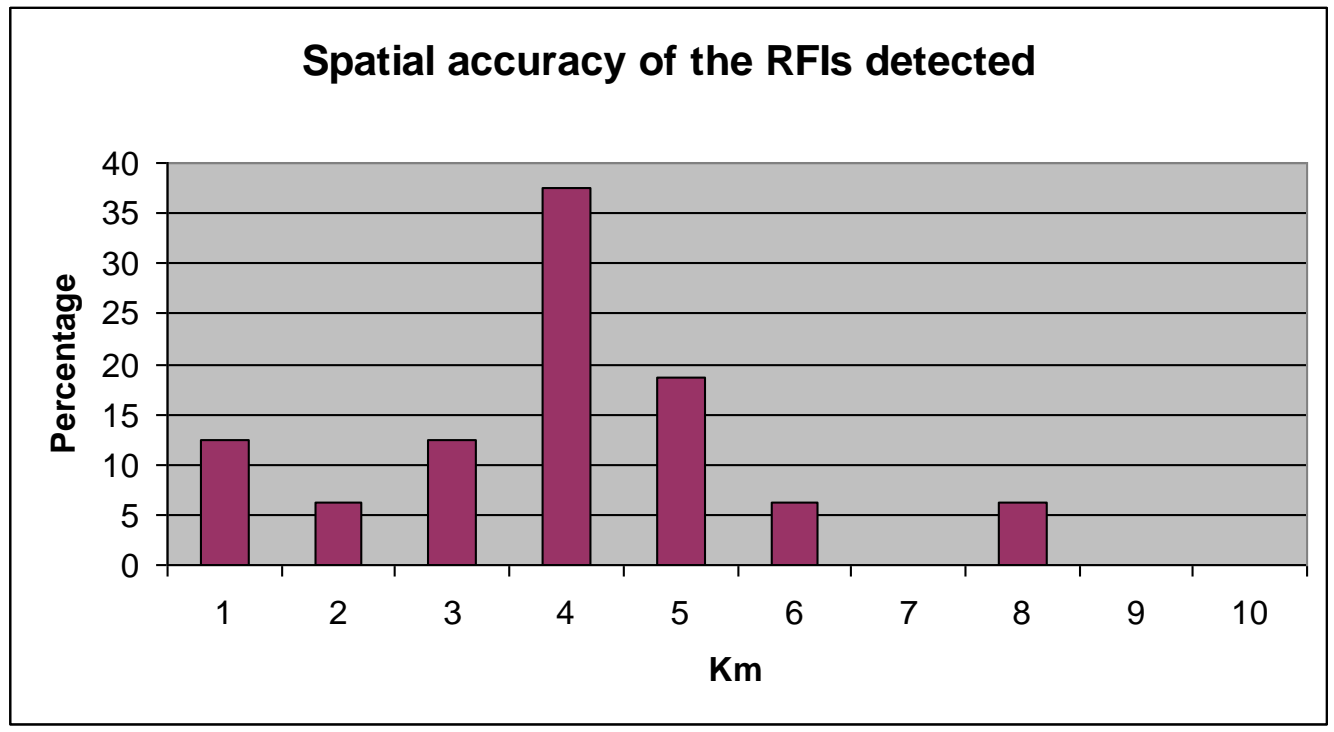

Figure 155: Spatial accuracy histogram of the RFIs detected. 
REPLACE THIS LINE WITH YOUR PAPER IDENTIFICATION NUMBER (DOUBLECLICK HERE TO EDIT) <

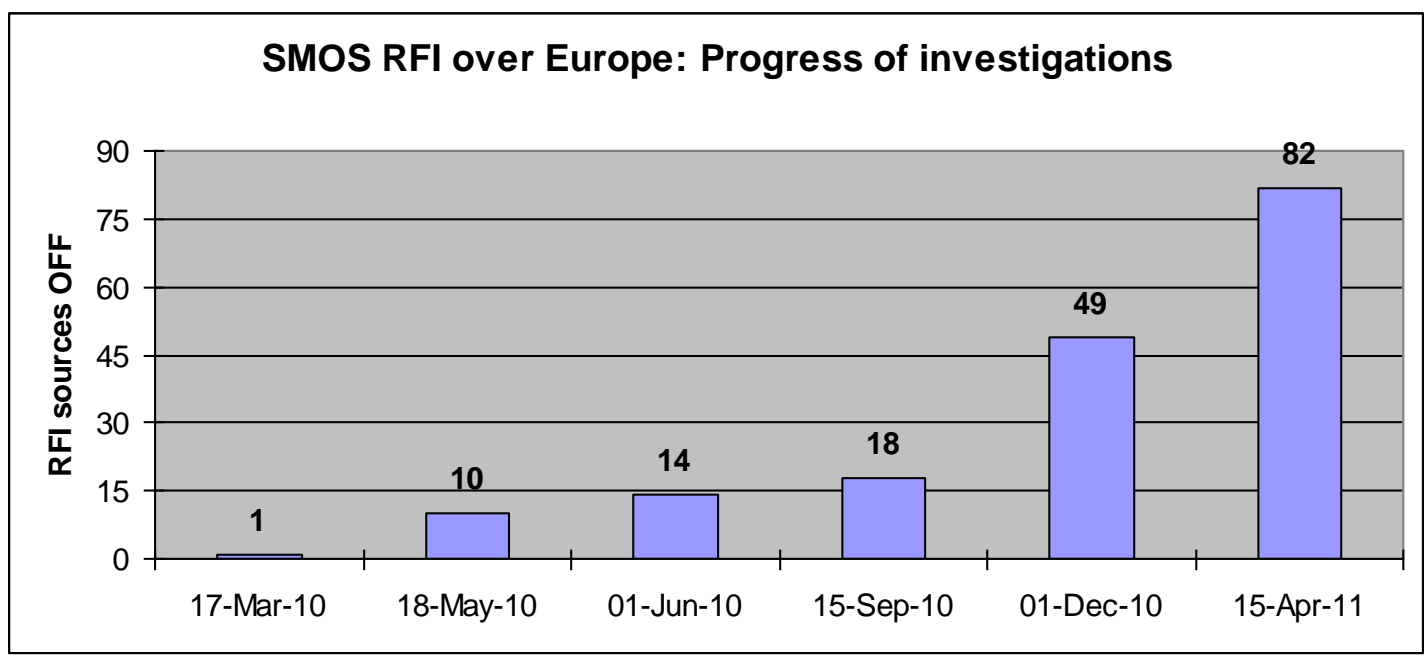

Figure 166: Evolution of the sources cancelled in Europe

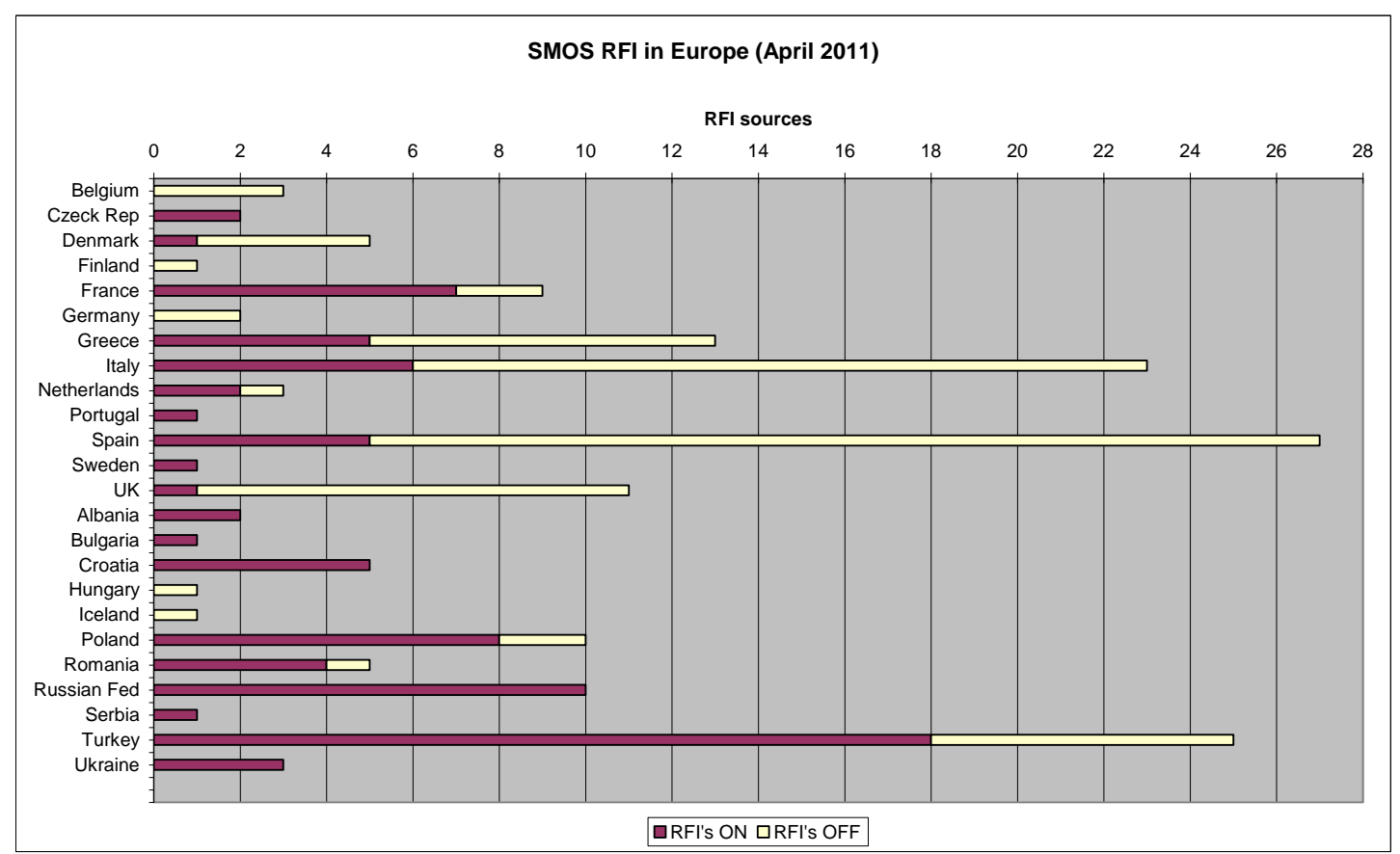

Figure 17: Distribution by countries of the sources active and cancelled in Europe (April 2011) 
Figure 18:

\section{SMOS}

measureme nt

ohservation
REPLACE THIS LINE WITH YOUR PAPER IDENTIFICATION NUMBER (DOUBLECLICK HERE TO EDIT) <
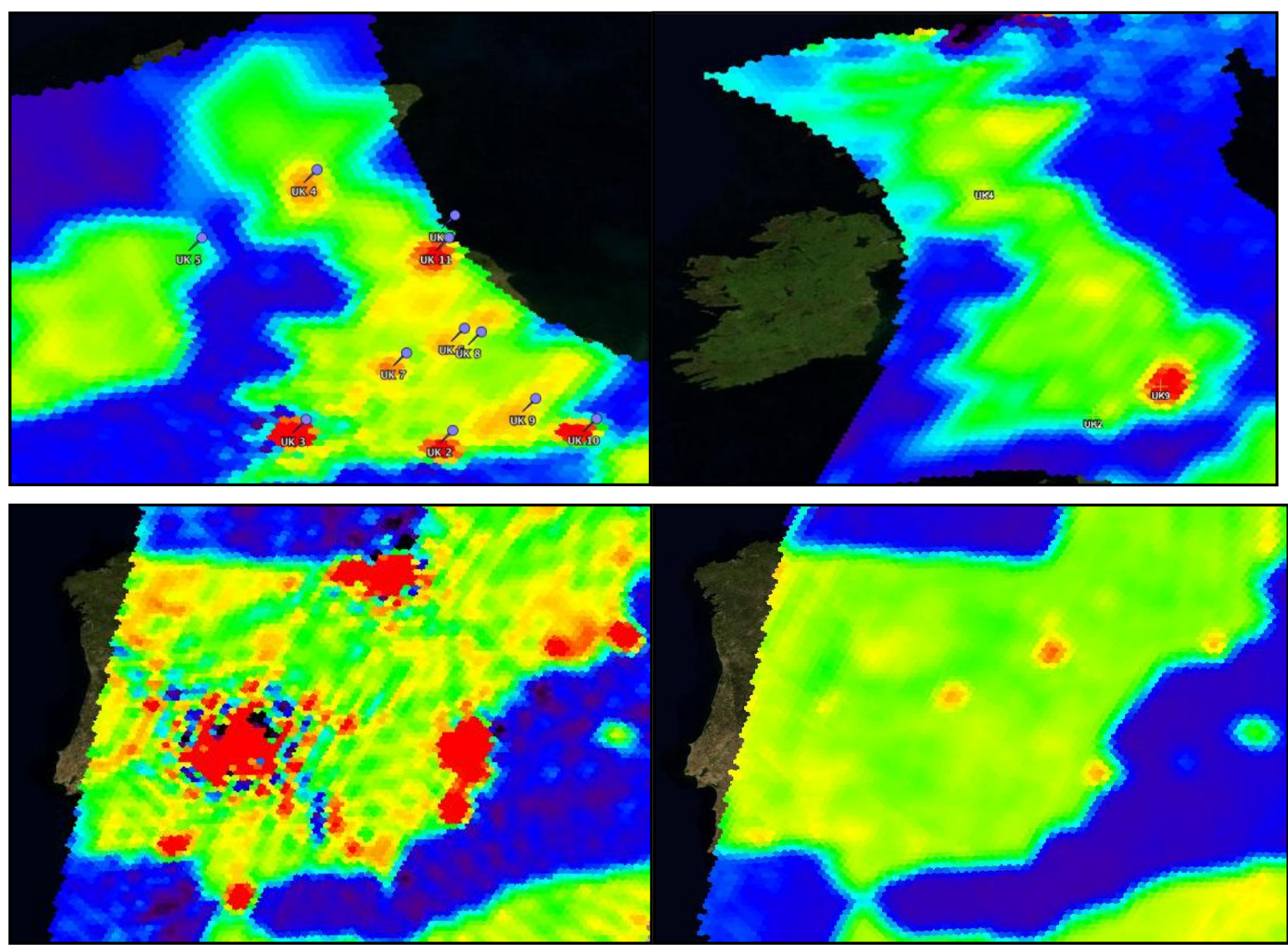

Figure 178: SMOS images in BT observed in the UK (top) and Spain (bottom) early in the mission (left) and the situation as of April 2011 (right) 